\title{
Artificially cemented sand under multiaxial loading
}

\author{
Lucas Festugato ${ }^{1, *}$, Marina Bellaver Corte ${ }^{1}$, Erdin Ibraim $^{2}$, and Andrea Diambra ${ }^{2}$ \\ ${ }^{1}$ Federal University of Rio Grande do Sul, Department of Civil Engineering, Porto Alegre, Brazil \\ ${ }^{2}$ University of Bristol, Department of Civil Engineering, Bristol, United Kingdom
}

\begin{abstract}
Distinct improvement techniques can be used when civil engineering structures are to be built on soils that do not present suitable mechanical characteristics. The soil improvement techniques can vary from compaction to chemical and mechanical stabilisation. This work focuses on the specific case of granular soils treated with low amount of cement. The study aims to investigate the behaviour of a cemented sand under multiaxial loading conditions. A series of advanced tests on reconstituted cemented sand were conducted in a Cubical Cell Apparatus (CCA) and exploration of material response including failure limits under different constant stress paths $\left(\theta=0^{\circ}\right.$ and $\left.\theta=120^{\circ}\right)$ in the octahedral $(\pi)$ plane were performed. Results showed strength is higher in vertical direction than in horizontal direction.
\end{abstract}

\section{Introduction}

Not rarely, soil properties may not suit the construction project characteristics and requirements. An alternative is the addition of cement to the soil matrix. Previous studies of soil cement mixtures have shown that the behaviour of the material is complex and it is affected by many factors, such as physical-chemical properties of the soil, the amount of cement and moisture of the mixture (e.g. [14]). [3] studied the effect of cement content and porosity on the unconfined compressive strength of a sandy soil cement with Portland cement. [5, 6] evaluated the tensile behaviour of clean granular cemented soils. The mentioned studies showed a given strength can be achieved by either an increase of cement content or a decrease of mixtures voids ratio. [7] proposed a unique relationship determining the strength of soils with fines cemented with Portland cement. [8] presented a theoretical derivation of artificially cemented granular soils strength. None of the mentioned investigations specifically delt with the multiaxial response of the cemented materials.

Other studies [9] analysed a lightly cemented sand. The authors describe that in the Vincentown formation the highly cemented lenses represent the final stage of cementation process, while less cemented samples represent intermediate stages in incomplete cycles of cementation. Other authors [10] showed that with a small amount of cement added on soil, it is possible to increase dynamic moduli and damping ratios of sands at low strain amplitudes.

This study investigates the behaviour of a lightly cemented sand under multiaxial loading conditions.

\section{Experimental program}

\footnotetext{
* Corresponding author: lucas@ufrgs.br
}

\subsection{Materials}

Hostun RF (S28) sand was used in this research. This sand has a high amount of siliceous $\left(\mathrm{SiO}_{2}>98 \%\right)$ and it has angular to sob-angular grain shape. The grain size distribution (Fig. 1) corresponds to uniformly graded medium, its physical characteristics are: mean grain size, $\mathrm{D}_{50}=0.32 \mathrm{~mm}$, coefficient of uniformity, $\mathrm{C}_{\mathrm{u}}=\mathrm{D}_{60} / \mathrm{D}_{10}=$ 1.70 , coefficient of gradation, $C_{g}=\left(D_{30}\right)^{2}\left(D_{10} D_{60}\right)=1.1$, maximun and minimum void ratio, $\mathrm{e}_{\max }=1.00, \mathrm{e}_{\min }=$ 0.62 , and specific gravity $\mathrm{G}_{\mathrm{s}}=2.65$.

The cementation agent used was a Portland cement of high initial strength (Type III, ASTM C 150-09 [11]). As the cement has a fast gain of strength, 7 days curing time of cemented sand samples was adopted in this research.

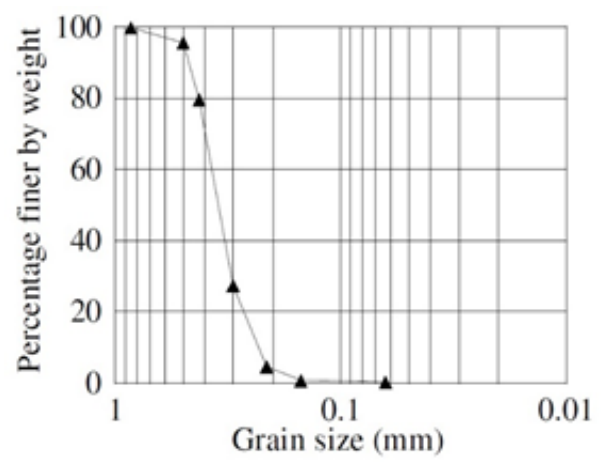

Fig. 1. Grain size distribution (Ibraim et al. 2011, [8]).

\subsection{Cubical cell apparatus}

The true triaxial apparatus provides the possibility of controlling the magnitude of the three principal stresses 
(Fig. 2) and strains under relatively well preserved uniformity of stresses and strains within a cuboidal sample, close to six degrees of freedom of general stress state [12]. The results presented on this paper come from tests performed on the apparatus developed at the University of Bristol [13]. The Cubical Cell Apparatus (CCA) consists of flexible boundaries through which the principal stresses are applied. The flexible boundaries are provided by a set of flexible cushions for $10 \times 10 \times 10 \mathrm{~cm}^{3}$ volume samples. Owing to the rigidity and the nature of the tested samples, in this research, mixted rigid-flexible boundary conditions were chosen for each material axes. The measurements of the sample displacements are conducted by the averaging of the measurements provided by three LVDTs placed on the flexible cushion face of all three axes. Three pressure transducers located immediately behind the flexible cushions complete the loading system.

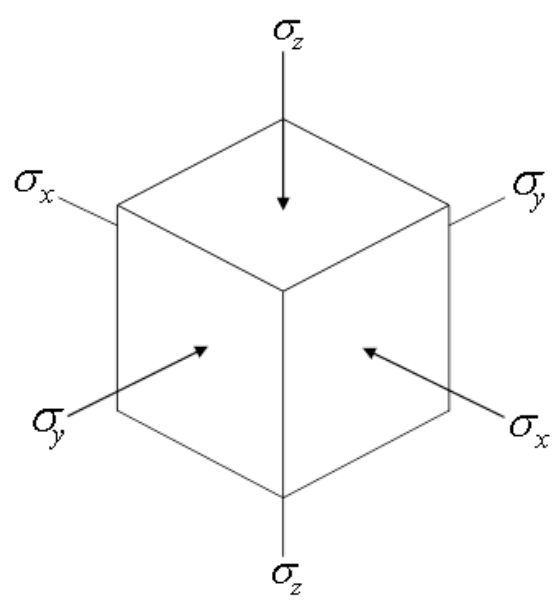

Fig. 2. True triaxial apparatus: independent control of three principal stresses.

\subsection{Specimen preparation}

Cubical specimens, $10 \mathrm{~cm}$ side, were manufactured to be tested in the cubical cell. Sand, cement and water were weighted and sand and cement mixed until a uniform consistence was achieved. The water was then added and the sand - cement composite mixed until a homogeneous material was obtained. The void ratio used in all samples was 0.74 . The amount of cement in all the mixtures was $1.8 \%$, calculated based on the mass of the dry sand. The amount of mixing water was based on the target moisture content, $10 \%$, by mass of dry soil and cement.

When by visual inspection was considered that the material appeared relatively homogeneous, the mixture was divided in three portions corresponding to the amount of the successive soil layers used for the fabrication of the samples. Each sample layer was statically compacted by the use of a steel square tamper, inside of a cubical stainless steel mould. Between layers the top surface of the bottom layer was scarified. After formation, the weight of mould+sample was measured and the sample was left inside the mould for one day, protected with plastic film and in a sealed plastic bag.
After one day, the sample was removed from the mould (Fig. 3), its dimensions measured and kept for curing in the plastic film for another 5 days in the environmentally controlled conditions of $22^{\circ} \mathrm{C}$ temperature and $60 \%$ humidity.

One day before the testing, the sample was removed from plastic and immersed in water for 24 hours, to minimize suction effects $[3,14,15]$.

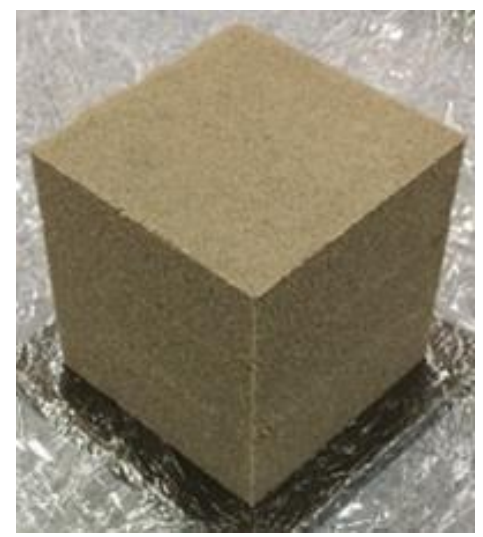

Fig. 3. Compacted sample.

\subsection{Test procedure}

The setup of the sample prior to the testing consisted of placing the sample against the three rigid walls, followed by installation of flexible cushions on the opposite sides and rigid platens including the LVDTs for sample displacement measurements. The three pressure transducers were then placed, and the connections with the air compressed system established for all three loading directions, $\mathrm{x}, \mathrm{y}$ and $\mathrm{z}$.

As the sample is in a saturated state, the test started with the consolidation procedure. Increments of $10 \mathrm{kPa}$ were applied isotropically on the three faces of the cube every 10 minutes, which is approximately the time required for samples to consolidate (no volumetric changes measured). The consolidation pressure for all the tests was $100 \mathrm{kPa}$. Once consolidation completed, the sample was sheared. Two different stress paths were applied, $\theta=0^{\circ}$ and $120^{\circ}$, which represent triaxial compression with $\sigma_{\mathrm{z}}$ and $\sigma_{\mathrm{y}}$ being the maximum principal stresses, respectively. In both tests, the intermediate principal stress parameter b (Eq. 1) is constant and equal to 0 .

$$
b=\frac{\sigma_{2}-\sigma_{3}}{\sigma_{1}-\sigma_{3}}
$$

In the xyz rectangular coordinate system, $\mathrm{z}$ represents the vertical direction while $\mathrm{x}$ and $\mathrm{y}$ are the horizontal directions. For both tests, the mean effective pressure,

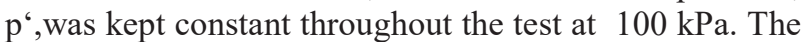
stress paths were generated in a stress control manner with $10 \mathrm{kPa}$ stress increase in one direction doubled by $5 \mathrm{kPa}$ stress decrease in the other two directions. 


\section{Results and discussions}

Fig. 4 shows the stress-strain responses over the principal directions for both $\theta=0^{\circ}$ (Fig. 4a) and $120^{\circ}$ (Fig. 4b) stress paths. The Lode angle, $\theta$, defines the direction the shear stress on the octahedral plane (Eq. 2).

$$
\theta=\tan ^{-1}\left(\frac{\sqrt{3}\left(\sigma_{y}^{\prime}-\sigma_{x}^{\prime}\right)}{2 \sigma_{z}^{\prime}-\sigma_{x}^{\prime}-\sigma_{y}^{\prime}}\right)
$$

Under $\theta=0^{\circ}$ stress path, the cemented material exhibited compressive strain in the vertical $\mathrm{z}$ direction and extension strains in $\mathrm{x}$ and $\mathrm{y}$ directions. For the $\theta=120^{\circ}$ stress path, the sample is compressed in the y direction and extension is taking place in $\mathrm{x}$ and $\mathrm{z}$ directions. As shown in Fig. 4, higher strain limits in the principal direction are observed for the test at $\theta=120^{\circ}$ compared with the test at $\theta=0^{\circ}$. As the tests are conducted in stresscontrolled mode, only the peak stresses can be obtained and once the failure occurs, the deformations increase steadily at a relatively high rate. The material behaviour is brittle and the occurence of the failure is marked by the arrows (Fig. 4). However, a relatively similar stress-strain response is observed for the directions where the stresses are reduced for both tests.

The effect of the different stress paths on strength can also be observed in Fig. 5, where the distortional stress, $\mathrm{q}_{\mathrm{z}}$ (Eq. 3), is presented with the distortional strain, $\varepsilon_{\mathrm{q}}$ (Eq. 4).

$$
\begin{gathered}
q=\sqrt{\frac{\left(\sigma_{y}^{\prime}-\sigma_{z}^{\prime}\right)^{2}+\left(\sigma_{z}^{\prime}-\sigma_{x}^{\prime}\right)^{2}+\left(\sigma_{x}^{\prime}-\sigma_{y}^{\prime}\right)^{2}}{2}} \\
\varepsilon_{q}=\frac{1}{3} \sqrt{2\left[\left(\varepsilon_{y}-\varepsilon_{z}\right)^{2}+\left(\varepsilon_{z}-\varepsilon_{x}\right)^{2}+\left(\varepsilon_{x}-\varepsilon_{y}\right)^{2}\right]}
\end{gathered}
$$

Under $\theta=0^{\circ}$ stress path conditions, the cemented sand strength appears to be higher than the strength recorded under $\theta=120^{\circ}$ stress path case. The higher strength is associated with lower volumetric contraction as shown in Fig. 6. Vertical arrows corresponding to the point of failure triggering are also shown in the Fig. 5 and 6.

While one may expect an isotropic response induced by a more uniform cementation process, it is possible that the low level of cementious material could not provide enough particle bonding to override the anisotropy induced by the fabrication process. Compaction during fabrication takes place over the vertical, z, direction, and this seems to control the material response in multiaxial loading conditions. Further tests with stress paths following different constant $\theta$ Lode angles are ongoing to further invetigate this point.

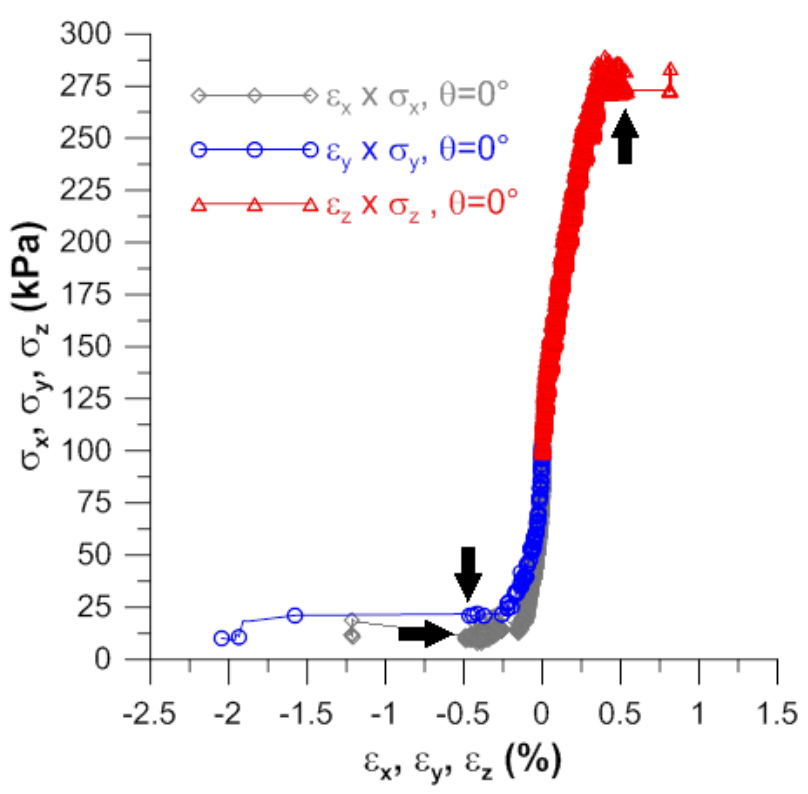

(a)

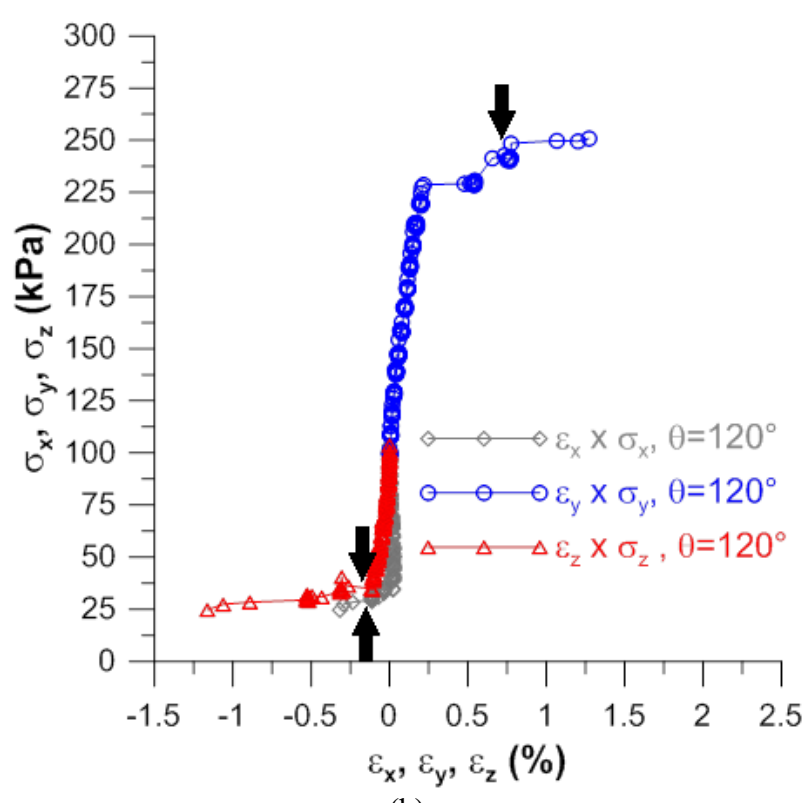

(b)

Fig. 4. Stress-strain curves of (a) $\theta=0^{\circ}$ and (b) $\theta=120^{\circ}$ stress paths. 


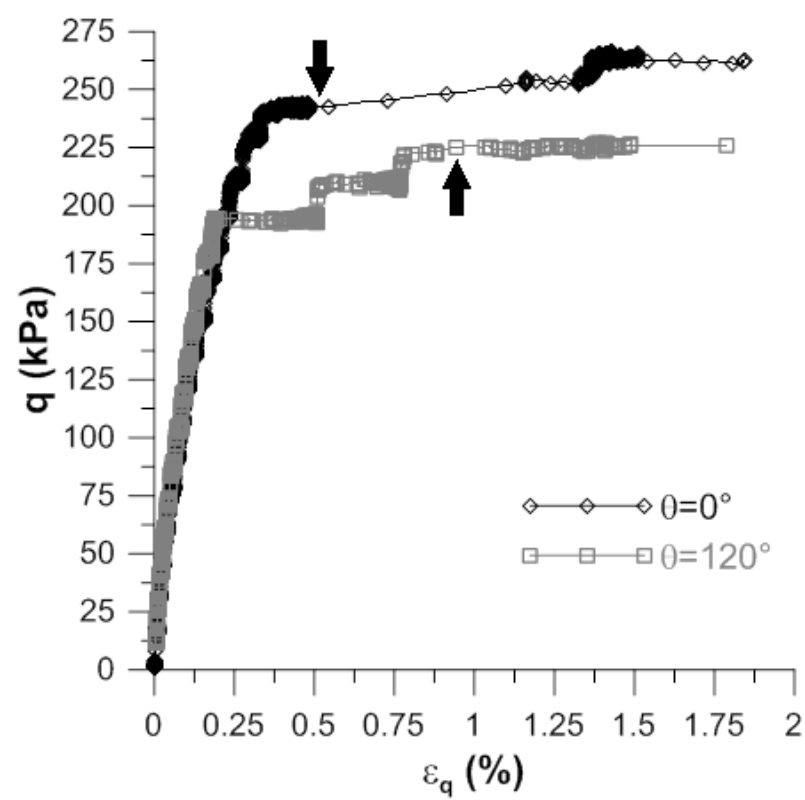

Fig. 5. Distortional stress, q, against distortional strain, $\varepsilon_{\mathrm{q}}$.

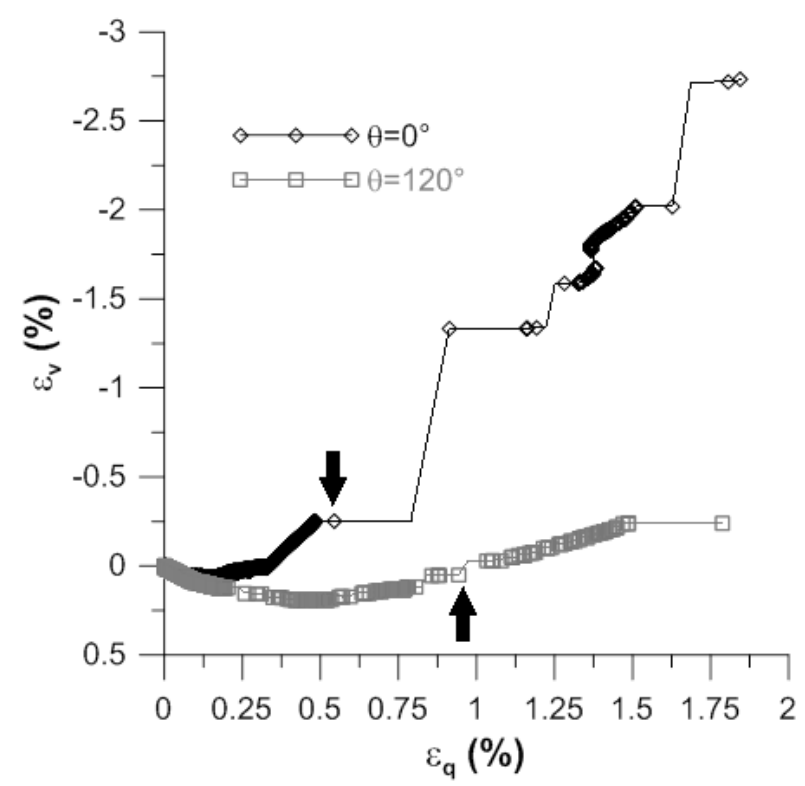

Fig. 6. Volumetric strain, $\varepsilon_{\mathrm{v}}$, against distortional strain, $\varepsilon_{\mathrm{q}}$.

\section{Conclusions}

Throught the comparison of true triaxial tests results on lightly cement sand, the effect of different stress paths could be observed. The strength of the studied samples tested over two different stress paths corresponding to $0^{\circ}$ and $120^{\circ}$ Lode angles was higher in $\mathrm{z}$ direction $\left(\theta=0^{\circ}\right.$ test) than in $y$ direction $\left(\theta=0^{\circ}\right.$ test $)$. It seems that the light cementation is not able to generate a material close to an isotropic condition.

Further tests are conducted with additional stress paths so that analytical formulation of the failure criterion for this type of soil mixture can be developed, including the study of the strength anisotropy, revealed in this paper.
Authors would like to express their gratitude to the Brazilian Reasearch Council (CNPq) for the financial support.

\section{References}

1. R. K. Moore, T. W. Kennedy, W. R. Hudson, Highway Res. Rec., 315, 64-80( 1970)

2. G. W. Clough, N. Sitar, R. C. Bachus, N. S. Rad, J. Geotech. Eng. Div., 107, 6, 799-817 (1981)

3. N. C. Consoli, D. Foppa, L. Festugato, K. S. Heineck, J. Geotech. Geoenv. Eng., 133, 2, 197- 205 (2007)

4. L. Festugato, M. B. Corte, J. Geotech. Geoenv. Eng., 144, 07018009 (2018)

5. N. C. Consoli, R. C. Cruz, M. F. Floss, L. Festugato, J. Geotech. Geoenv. Eng., 136, 759-763 (2010)

6. N.C. Consoli, S. Marques, M. F. Floss, L. Festugato, J. Mat. Civ. Eng., 29, 06017004 (2017)

7. N.C. Consoli, P. M. V. Ferreira, C. Tang, S. Marques, L. Festugato, M.B. Corte, Soils and Found., 56, 10821088 (2016)

8. A. Diambra, E. Ibraim, A. Peccin, N.C. Consoli, L. Festugato, J. Geotech. Geoenv. Eng., 143, $04017003-$ 1-04017003-9 (2017)

9. S. K. Saxena, R. M. Lastrico, J. Geotech. Eng. Div., 104, 1449-1464 (1978)

10. S. K. Saxena, A. S. Avramidis, K. R. Reddy, Can. Geotech. J., 32, 353-368. (1988)

11. ASTM. Standard specification for Portland cement, ASTM C 150-09. West Conshohocken, PA: ASTM International (2009)

12. S. Hamlin, E. Ibraim, M. Lings, D. M. Wood, I. Caravetta, J. F. Camenen, Def. Char. Geom., 6, 390397 (2015)

13. T. Sadek, PhD Thesis, University of Bristol (2006)

14. N. C. Consoli, M. B. Corte, L. Festugato, Geosysth. Int. 18, 409-414 (2012)

15. N. C. Consoli, A. V. da Fonseca, S. R. da Silva, R. C. Cruz, A. Fonini, Géotechnique, 62, 177-183 (2012) 